Journal of

Cancer Research and Therapeutic Oncology

\title{
The Prostate Cancer Road Map Hypothesis in 49 Countries; from Iron-Defi- ciency Anemia (IDA) to Death
}

\section{Cornelli Umberto $\mathrm{MD}, \mathrm{PhD}^{1, *}$, Belcaro Giovanni $\mathrm{MD}, \mathrm{PhD}^{2}$, Recchia Martino $\mathrm{PhD}^{3}$}

${ }^{1}$ Loyola University School of Medicine Chicago USA

${ }^{2}$ IRVINE LABS, University of Chieti-Italy

${ }^{3}$ University of Lugano-Switzerland

*Corresponding author: Cornelli Umberto, Loyola University School of Medicine Chicago USA; E-mail: ucornelli@gmail.com

Received Date: September 21, 2019 Accepted Date: October 21, 2019 Published Date: October 24, 2019

Citation: Cornelli Umberto (2019) The Prostate Cancer Road Map Hypothesis in 49 Countries; from Iron-Deficiency Anemia (IDA) to Death. J Cancer Res Therap Oncol 7: 1-11.

\begin{abstract}
Background: During the follow up analysis of the San Valentino (Italy) screening of cardiovascular diseases of death due to prostate cancer (PCa) in 2016 had in common iron deficiency anemia (IDA) in 2000.

Methods: An analysis was conducted in 49 countries to determine the relationship between PCa, IDA and other 16 variables possibly connected with IDA. Data were retrieved from the WHO records (2018) using the ASDRs (Age-Standardized Death Rate x 100000 population) in 49 countries limited to the years 2000, 2010 and 2016. The 49 selected countries (SC) were those considered by WHO "with high completeness and quality of cause-of-death assignment" and "may be used for priority setting and policy evaluation". PCa, IDA, and 16 diseases: tuberculosis, gonorrhea, syphilis, chlamydia in females, other sexually transmitted diseases (STDs in both genders), diarrheal diseases, gastric ulcers, cirrhosis, IDA, HIV, digestive diseases, respiratory infections, alcohol, and drugs addictions. The correlations with PCa were calculated using the Cluster analysis followed by the Multivariate analysis and the Residual Normal Quantile Plot.

Results: IDA, HIV, chlamydia in females, and digestive diseases were significantly correlated with PCa. All the other variables resulted not correlated.

Conclusions: The road map of PCa seems to be IDA, immune depression, followed by infections caused by chlamydia. Digestive diseases- other than gastric ulcers and cirrhosis- are only minimally predictive. Chlamydia vaccination is suggested as a possible solution to protect from PCa. Prospective, long-term studies should be considered
\end{abstract}

Keywords: prostate cancer; iron deficiency anemia; HIV; chlamydia

(C)2019 The Authors. Published by the JScholar under the terms of the Creative Commons Attribution License http://creativecommons.org/licenses/ by/3.0/, which permits unrestricted use, provided the original author and source are credited. 


\section{Introduction}

The epidemiological study in San Valentino (Italy) started in 1997 aimed at the screening of cardiovascular diseases $[1,2]$. During the follow up of the participants in 2016 the attention was focused on 3 males who died for prostate cancer (PCa). Going back to their records, the only observation common to these patients was the presence of IDA beginning in 2000, without any infection or hematuria in the urines. These subjects partially recovered their hematocrit after 2000 with an appropriate diet (including an increase of meat intake and vitamin $\mathrm{C}$ supplementation). However, full recovery was not observed in the following years (2003 and 2004). These subjects were within the normal range for other blood tests including glucose, lipids and for clinical observations. The IDA recovery was managed at GP level. In 2010 a diagnosis of PCa was made and they eventually died in 2016.

The PCa is the fifth leading cause of death in man summing up about 300,000 cases in 2015 [3]. The pathogenesis has been studied [4-6] but still is unclear. The suggestion about foods and genetic trait characteristics [7] had emerged and the screening of Prostate-Specific Antigen (PCA) was suggested as an effective tool for earlier diagnosis with the aim of reducing deaths [8]. Age is considered the major risk factor [9], with race, socioeconomic status; PCa is more frequent in the underdeveloped countries $[10,11]$ and death is related to the stage of cancer, the possible management, and its affordability, metastatic conditions, and type of therapy $[12,13]$. Preliminary studies concerning sexually transmitted infections (STDs) or prostatitis showed that their influence on PCa is unclear [14]. Some studied ruled out a possible role for gonorrhea and syphilis [15].

However, a systematic analysis of 47 studies concluded that gonorrhea was associated with PCa, whereas any other STDs, either bacterial or viral, were excluded [16]. IDA was never considered as a connecting or facilitating factor for PCa and the observation made in the San Valentino epidemiological study suggested investigating possible correlations of PCa with some of the most common diseases possibly causing IDA.

The analysis was conducted on all available data within the WHO records concerning total mortality for PCa in term of ASDRs (Age-Standardized-Death Rate x 100000 population) compared to ASDRs of IDA and diseases possibly causing IDA considering the year 2000 [17].

\section{Material and Methods}

\section{Criteria of choice for the variables and period of time}

The Age-Standardized Death Rate $\mathrm{x} 100000$ population (ASDRs), and Crude Death Rate x 100000 population (CDR) for
PCa were considered. ASDRs were chosen as main variables because -unlike CDR prevalence/incidence measures - are free of the bias related to age.

The ASDRs data listed as Global Health Estimates 2016 published in 2018 were used [17]; PCa values were compared to IDA and other diseases known to cause IDA. Data regarding males were considered for all the variables, whereas for females the research was limited to STDs and chlamydia only.

\section{Data collection}

The values up to the fourth decimal place were taken from the WHO records relative to the selected ASDRs for 2000, 2010 and 2016 and CRDs for the years 2000 and 2016 only.

\section{Criteria of choice of the countries}

The data used for correlations were relative to the 49 countries (selected countries or SC) considered by WHO "with high completeness and quality of cause-of-death assignment" that "may be compared and time series may be used for priority setting and policy evaluation" (see Table 1). For the calculation of the CDR were considered all the 185 countries as listed in the WHO report. The male population in the respective years was taken from the same report.

\section{Statistical evaluation}

A five steps analysis was followed [18-21]. The first was the calculation of the averages \pm SD for all the variables in order to obtain a general picture, followed by the $\%$ increase for each variable and the U Mann-Whitney test for differences between the years 2000 and 2016.

The second step was a Cluster Variables Method analysis for grouping similar variables into representative groups, using the dimension-reduction method instead of large set variables in modeling. Four clusters were identified, each represented by the main representative variable. A Multiple Regression analysis followed as a third step to isolate variables more correlated with PCa. The fourth step was to determine the reliability of this last analysis using Q-Q plot (quantity of the data Vs quantiles of distribution) which can produce a linear regression only in case of observations with a normal distribution. The fifth step was the analysis of the variance to determine the significance of the main variables connected to the PCa and the relative Prediction Profilers. The JMP14.20 Programs 2019 of SAS Institute were used for the analysis. 


\section{Results}

\section{Population, CRD, and ASDRs}

In the 185 countries, the total male population is reported in Table 1. In 2000 the 49 SC the male's population was of about $19.8 \%$ of the total, whereas in 2016 was $18.0 \%$. In the same countries, in 2000 the number of death for PCa was the
$51.1 \%$ of the total compared to $44.1 \%$ in 2016 . The figures indicate that the 49 SC represents a reliable cohort to determine the correlations among the variables related to PCa. Similar proportions limited to the population were determined for females. Comparing data of 2016 and 2000 almost all the ASDRs considered showed a reduction (see Table 2).

\begin{tabular}{|l|l|l|l|l|ll|}
\hline \multirow{2}{*}{ Year } & \multicolumn{3}{|l|}{ Population males $10^{6}$} & \multicolumn{3}{l|}{ CRD $10^{3}$ for PCa } \\
\cline { 2 - 5 } & 185 countries & 49 SC & \% of 49 SC & $\begin{array}{l}185 \text { countries } \\
\text { 49 SC }\end{array}$ & \% of 49 SC \\
\hline 2000 & 3063.097 & 606.482 & 19.8 & 247.771 & 126.618 & 51.1 \\
\hline 2016 & 3717.324 & 669.671 & 18.0 & 352.255 & 155.213 & 44.1 \\
\hline \multirow{2}{*}{ Year } & \multicolumn{3}{|l|}{ Population females $10^{6}$} & & & \\
\cline { 2 - 4 } & 185 countries & 49 SC & \% of 49 SC & & & \\
\hline 2000 & 3024.847 & 640.335 & 21.2 & & & \\
\hline 2016 & 3673.749 & 738.321 & 20.1 & & & \\
\hline
\end{tabular}

Table 1: Males Population and CRD for PCa in the 185 countries compared to the 49 SC and relative percentages

\begin{tabular}{|c|c|c|c|c|c|c|}
\hline \multirow{2}{*}{ Diseases } & \multirow[b]{2}{*}{ GHE } & \multirow{2}{*}{$\begin{array}{l}\text { Gen- } \\
\text { der } \\
M / F\end{array}$} & \multicolumn{3}{|c|}{ ASDRs values Mean \pm SD } & \multirow{2}{*}{$\begin{array}{l}\text { \% } 2016 \\
\text { Vs } 2000\end{array}$} \\
\hline & & & 2000 & 2010 & 2016 & \\
\hline Prostate cancer $(\mathrm{PCa})$ & 740 & M & $22.8 \pm 16.11$ & $22.5 \pm 18.27$ & $20.3 \pm 15.55^{\mathrm{a}}$ & -11.0 \\
\hline Iron-deficiency anemia [IDA] & 580 & M & $0.89 \pm 1.635$ & $0.73 \pm 1.714$ & $0.56 \pm 0.807^{\mathrm{a}}$ & -37.0 \\
\hline Tuberculosis (TBC) & 30 & M & $6.5 \pm 10.31$ & $3.4 \pm 5.53$ & $2.3 \pm 3.26^{\mathrm{a}}$ & -64.6 \\
\hline $\begin{array}{l}\text { STD (sexually transmitted diseases) } \\
\text { excluding HIV }\end{array}$ & 40 & M & $0.10 \pm 0.163$ & $0.05 \pm 0.102$ & $0.07 \pm 0.201$ & -30.0 \\
\hline $\begin{array}{l}\text { STD (sexually transmitted diseases) } \\
\text { excluding HIV }\end{array}$ & 40 & $\mathrm{~F}$ & $0.23 \pm 0.283$ & $0.11 \pm 0.143$ & $0.09 \pm 0.114^{\mathrm{a}}$ & -60.9 \\
\hline Syphilis & 50 & M & $0.10 \pm 0.162$ & $0.06 \pm 1.007^{\mathrm{a}}$ & $0.04 \pm 0.073^{\mathrm{a}}$ & -40.0 \\
\hline Chlamydia (Chlamy) & 60 & $\mathrm{~F}$ & $0.02 \pm 0.025$ & $0.01 \pm 0.014$ & $0.01 \pm 0.010^{\mathrm{a}}$ & -50.0 \\
\hline Gonorrhea (Gono) & 70 & M & $0.003 \pm 0.0039$ & $0.001 \pm 0.0015$ & $0.001 \pm 0.0008^{\mathrm{a}}$ & -66.7 \\
\hline HIV/AIDS & 100 & M & $7.3 \pm 22.44$ & $6.5 \pm 13.27$ & $5.1 \pm 13.62$ & -30.1 \\
\hline Diarrheal diseases (Diarrh) & 110 & M & $2.7 \pm 7.33$ & $1.6 \pm 3.29$ & $1.4 \pm 2.31$ & -48.1 \\
\hline Parasitic and vectorial diseases (PVD) & 210 & M & $0.77 \pm 1.953$ & $0.49 \pm 1.244$ & $0.42 \pm 0.957^{\mathrm{a}}$ & -45.5 \\
\hline Respiratory infections (R Inf) & 380 & $\mathrm{M}$ & $31.9 \pm 25.26$ & $22.3 \pm 16.24$ & $20.4 \pm 13.34^{\mathrm{a}}$ & -36.1 \\
\hline Alcohol use disorders (Al Dis) & 860 & $\mathrm{M}$ & $7.3 \pm 7.55$ & $6.4 \pm 6.23$ & $5.4 \pm 4.89^{\mathrm{a}}$ & -26.0 \\
\hline Drug use disorders (Dr Dis) & 870 & $\mathrm{M}$ & $3.6 \pm 3.17$ & $3.7 \pm 3.37$ & $3.5 \pm 3.28$ & -2.8 \\
\hline Digestive diseases (Dig Dis) & 1210 & $\mathrm{M}$ & $43.6 \pm 24.73$ & $38.6 \pm 23.70$ & $34.1 \pm 19.80^{\mathrm{a}}$ & -26.3 \\
\hline Peptic ulcer (P ulc) & 1220 & M & $4.2 \pm 2.80$ & $2.8 \pm 2.19$ & $2.5 \pm 2.26^{\mathrm{a}}$ & -40.5 \\
\hline Cirrhosis (Cirr) & 1230 & M & $22.1 \pm 18.31$ & $21.0 \pm 18.15$ & $17.8 \pm 14.52^{\mathrm{a}}$ & -19.5 \\
\hline Total ASDRs in the 49 SC & & M & $847.0 \pm 245.9$ & $703.3 \pm 248.66$ & $633.9 \pm 219.14^{\mathrm{a}}$ & -25.1 \\
\hline
\end{tabular}

Table 2. ASDRs of diseases considered in the analysis for the years between 2000 and 2016: mean values \pm SD and $\%$ average decrease $\mathrm{GHE}=$ Global health Estimation code

${ }^{\mathrm{a}}=$ Mann-Whitney U test: 2016 Vs 2000 p $<0.05$ 
In terms of mean values, the total ASDRs were significantly improved (-25\%). However, in most of the diseases, the variances were very high, indicating that the averages and \% reductions have to be considered with prudence. For HIV, diarrheal diseases, and drug use disorders the differences were not statistically significant. PCa and IDA were instead significantly reduced respectively by $11 \%$ and $37 \%$. Comparing ASDRs with dimensions similar to PCa values or those $>20$, the most consistent improvements were found for infectious and parasitic diseases $(-41.7 \%)$, followed by respiratory infections, digestive diseases and cirrhosis (respectively $-36.1 \%,-26.3 \%,-19.5 \%$ ). For diseases with average ASDRs between 4 to 8 , the most con- sistent reduction was found for TBC (-64.6\%) followed by gastric ulcer $(-40.5 \%)$ and alcohol abuse $(-26 \%)$.

For the rarer diseases with ASDRs $<, 1$ the most evident reduction was shown for gonorrhea (-66.7 \%) and parasitic and vectorial diseases (-45.5\%).

In females, the only ASDRs considered were STDs and Chlamydia both showing a reduction of $\geq 50 \%$.

\section{Population and PCa trends}

Table 3 summarizes the data on the male population increase and the relative ASDRs for PCa by country.

\begin{tabular}{|c|c|c|c|c|c|c|}
\hline \multirow{2}{*}{$\begin{array}{l}\text { Gender } \\
\text { Year }\end{array}$} & \multicolumn{3}{|c|}{$\mathrm{N}$ Males $\left(\mathrm{x} 10^{3}\right)$} & \multicolumn{3}{|c|}{ PCa ASDRs Males } \\
\hline & 2000 & 2016 & $\%$ incr & 2000 & 2016 & $\%$ incr \\
\hline \multicolumn{7}{|l|}{ Country } \\
\hline Armenia & 1440.92 & 1375.25 & -4.6 & 8.93 & 14.80 & +65.7 \\
\hline Australia & 9511.52 & 12020.35 & 26.4 & 23.35 & 15.24 & -34.7 \\
\hline Austria & 3916.40 & 4268.48 & 9.0 & 22.99 & 13.94 & -39.4 \\
\hline Bahamas & 145.10 & 191.54 & 32.0 & 59.31 & 54.01 & -8.9 \\
\hline Belgium & 50348.20 & 5590.81 & 11.1 & 22.06 & 15.67 & -39.4 \\
\hline Brazil & 86623.32 & 10283.10 & 17.8 & 27.30 & 20.51 & -24.9 \\
\hline Brunei & 168.75 & 217.90 & 29.1 & 13.52 & 16.40 & +21.3 \\
\hline Canada & 15225.06 & 18002.96 & 18.2 & 21.04 & 12.30 & -41.5 \\
\hline Chile & 7546.04 & 8870.61 & 17.6 & 25.48 & 24.24 & -4.9 \\
\hline Croatia & 2131.75 & 2030.46 & -4.8 & 18.33 & 20.02 & +9.2 \\
\hline Cuba & 5594.31 & 5741.37 & 2.6 & 33.52 & 30.27 & +3.2 \\
\hline Czechia & 5005.61 & 5214.70 & 4.2 & 23.04 & 16.48 & -28.5 \\
\hline Denmark & 2642.89 & 2840.81 & 7.5 & 29.54 & 23.13 & -21.7 \\
\hline Estonia & 652.56 & 614.40 & -5.8 & 26.40 & 28.44 & +7.7 \\
\hline Finland & 2352.58 & 2710.01 & 7.0 & 23.04 & 15.95 & -30.8 \\
\hline France & 29223.78 & 31811.65 & 8.9 & 23.46 & 13.21 & -43.7 \\
\hline Germany & 39680.44 & 40313.09 & 8.7 & 21.30 & 15.38 & -27.7 \\
\hline Grenada & 50.24 & 81.59 & 62.4 & 85.24 & 70.21 & -17.6 \\
\hline Guatemala & 5716.73 & 8159.45 & 42.7 & 19.26 & 16.32 & -15.3 \\
\hline Hungary & 4862.65 & 4637.69 & -4.6 & 22.62 & 17.16 & -24.1 \\
\hline Iceland & 140.34 & 166.78 & 18.8 & 25.79 & 21.06 & -18.3 \\
\hline Ireland & 1914.25 & 2353.74 & 22.9 & 23.20 & 16.21 & $-30,1$ \\
\hline Israel & 2965.57 & 4065.87 & 37.1 & 13.97 & 9.23 & -34.1 \\
\hline Italy & 27979.90 & 28943.65 & 4.1 & 14.35 & 9.90 & -31.0 \\
\hline Japan & 62929.57 & 62400.68 & -0.8 & 7.55 & 6.52 & -13.7 \\
\hline Kyrgyzstan & 2432.99 & 2953.38 & 21.4 & 6.29 & 5.62 & -10.7 \\
\hline Latvia & 1095.57 & 904.74 & -17.4 & 19.54 & 26.88 & +37.6 \\
\hline Lithuania & 1638.98 & 1339.62 & -18.3 & 23.63 & 25.85 & +9.41 \\
\hline Luxembourg & 214.79 & 298.22 & 34.7 & 22.54 & 11.73 & -48.0 \\
\hline Malta & 197.66 & 215.54 & 9.0 & 17.04 & 10.79 & -36.7 \\
\hline Mauritius & 587.69 & 624.07 & 6.1 & 9.14 & 9.98 & +9.1 \\
\hline Mexico & 50506.62 & 63501.51 & 25.7 & 15.86 & 13.97 & -11.9 \\
\hline Netherlands & 7888.74 & 8448.04 & 7.1 & 26.79 & 17.94 & -33.0 \\
\hline
\end{tabular}




\begin{tabular}{|c|c|c|c|c|c|c|}
\hline New Zealand & 1893.98 & 2291.89 & 21.9 & 26.73 & 16.44 & -38.5 \\
\hline Norway & 2229.01 & 2648.48 & 18.8 & 32.63 & 22.76 & -30.3 \\
\hline Rep. of Korea & 23775.81 & 25419.45 & 6.9 & 5.59 & 6.44 & +15.2 \\
\hline Moldova & 2010.77 & 1949.21 & -3.1 & 5.77 & 13.83 & +132.1 \\
\hline Romania & 10825.16 & 9583.68 & -12.5 & 11.70 & 14.13 & +20.8 \\
\hline Saint Vincent \& Grenadines & 54.33 & 55.31 & 1.8 & 80.01 & 84.63 & +5.8 \\
\hline Slovakia & 2621.67 & 2646.52 & 0.9 & 21.73 & 22.72 & +4.6 \\
\hline Slovenia & 970.77 & 1031.28 & 6.2 & 24.97 & 21.00 & -15.9 \\
\hline Spain & 20077.28 & 22729.18 & 12.1 & 18.04 & 11.42 & -36.7 \\
\hline Sweden & 4392.26 & 4920.08 & 12.0 & 30.68 & 21.64 & -29.5 \\
\hline Switzerland & 3501.52 & 4160.14 & 18.3 & 26.06 & 16.31 & -37.4 \\
\hline Macedonia & 1019.34 & 1040.49 & 2.1 & 11.48 & 14.68 & +27.8 \\
\hline Trinidad and Tobago & 630.61 & 672.98 & 6.7 & 55.90 & 57.89 & +3.6 \\
\hline United Kingdom & 28772.32 & 32443.20 & 13.0 & 22.68 & 17.53 & -22.7 \\
\hline United States of America & 138883.47 & 159423.60 & 14.8 & 18.82 & 12.84 & -31.8 \\
\hline Uzbekistan & 12356.1 & 15672.43 & 35.0 & 1.81 & 1.96 & +8.4 \\
\hline Total & 606482.26 & 669670.90 & & & & \\
\hline Mean & & & $9.6^{\text {à }}$ & 23.803 & 20.256 & $-10.9^{a}$ \\
\hline SD & & & 25.33 & 16.3039 & 15.5519 & 31.91 \\
\hline
\end{tabular}

Table 3. Males Population (N) ASDRs in the years 2000 and 2016 and relative death for PCa reported as Age Standardized Death Rates x 100000 population (ASDRs). Data of the 49 SC "with high completeness and quality of cause-of-death assignment" according to the WHO [17]; \% modification 2106/2000 of the mean values ${ }^{\mathrm{a}}=$ Mann-Whitney U test; 2016 Vs 2000 p $<0.05$

In the period between 2000 and 2016, the increase of population was $9.6 \%$, whereas the ASDRs for PCa were significantly reduced as an average of $10.9 \%$ despite a very large variance ( $p<0.05$; Mann-Whitney $U$ test). Even though in most of the countries a reduction of ASDRs was shown, a consistent increase was found in some countries (particularly in Eastern
European countries e.g., Moldova, Macedonia, Armenia, Latvia) with large fluctuation.

\section{Cluster analysis}

The Cluster analysis identified four clusters and the most represented variables are reported in Table 4 .

\begin{tabular}{|c|c|c|}
\hline Cluster & Number of members & Disease \\
\hline 1 & 8 & $\begin{array}{l}\text { Sexually transmitted diseases (STDs) } \\
\text { Syfilis } \\
\text { Intestinal Diseases (Int Dis) } \\
\text { Parasitic and vectorial diseases (PVD) } \\
\text { Diarrhea } \\
\text { STDs females } \\
\text { HIV(AIDS (HIV) } \\
\text { Iron deficiency anemia (IDA) }\end{array}$ \\
\hline 2 & 5 & $\begin{array}{l}\text { Digestive Diseases (Dig Dis) } \\
\text { Cirrhosis } \\
\text { Peptic ulcer } \\
\text { Alcohol-related disorders (Al Dis) } \\
\text { Tuberculosis (TBC) }\end{array}$ \\
\hline 3 & 2 & $\begin{array}{l}\text { Respiratory infections (R inf) } \\
\text { Chlamydia in females (Chlamy) }\end{array}$ \\
\hline 4 & 2 & $\begin{array}{l}\text { Drug use disorders (Dr Dis) } \\
\text { Gonorrhea (Gono) }\end{array}$ \\
\hline
\end{tabular}

Table 4. Cluster summary of the variables recorded in 2000 in relation to PCa in 2016. 
The variables within each cluster were similar to each other, but the difference from those included in the closest clusters. Using all of them in a multiple regression process was possible to adjust the comparison for any confounder since two or more related variables contained the same information.

IDA and five other variables were selected corresponding to the highest $\mathrm{R}$ squared values for $\mathrm{PCa}$ within the correspondent cluster as reported in Table 5.

\begin{tabular}{|l|l|l|l|}
\hline Cluster & Disease & $\begin{array}{l}\text { R square value } \\
\text { within own } \\
\text { cluster }\end{array}$ & $\begin{array}{l}\text { R square value } \\
\text { with the closest } \\
\text { cluster }\end{array}$ \\
\hline 1 & HIV & 0.710 & 0.181 \\
\hline 1 & IDA & 0.650 & 0.298 \\
\hline 2 & Dig Dis & 0.948 & 0.405 \\
\hline 3 & Rinf & 0.808 & 0.185 \\
\hline 3 & Chlamy & 0.809 & 0.476 \\
\hline 4 & Dr Dis & 0.651 & 0.169 \\
\hline
\end{tabular}

Table 5. R squared values of the selected variables Vs PCa and R square values with the closest cluster

Dig Dis = Digestive diseases; $\mathrm{R}$ inf = respiratory infections; Chlamy = chlamydia in females; Dr Dis = Drug use disorders .

The Step wise analysis selected the definitive "package" of variables to be considered for the Multiple Regression model together with anemia as reported in Table 6.

\begin{tabular}{|l|l|}
\hline Disease & Prob $>$ F \\
\hline IDA & $3.30 \mathrm{e}-7$ \\
\hline HIV & 0.00020 \\
\hline Chlamy & 0.00045 \\
\hline Dig Dis & 0.03186 \\
\hline R inf & 0.06245 \\
\hline Dr dis & 0.75036 \\
\hline
\end{tabular}

Table 6. Step Wise Regression: the probability of correlation with PCA

Dig Dis = Digestive diseases; $\mathrm{R}$ inf = respiratory infections; Chlamy = Chlamydia in females; Dr Dis = Drug use disorders; Prob $=$ probability.

Respiratory infections and drug use disorders were not significant therefore were excluded from the following Q-Q analysis plot (Residual Normal Quantile Plot).

The Q-Q plot calculated for the remaining four variables was linear ( $\mathrm{R}$ square value of 0.8493 ) indicating that the relative values were distributed normally within a probabilistic band of $95 \%$ as reported in Figure 1.

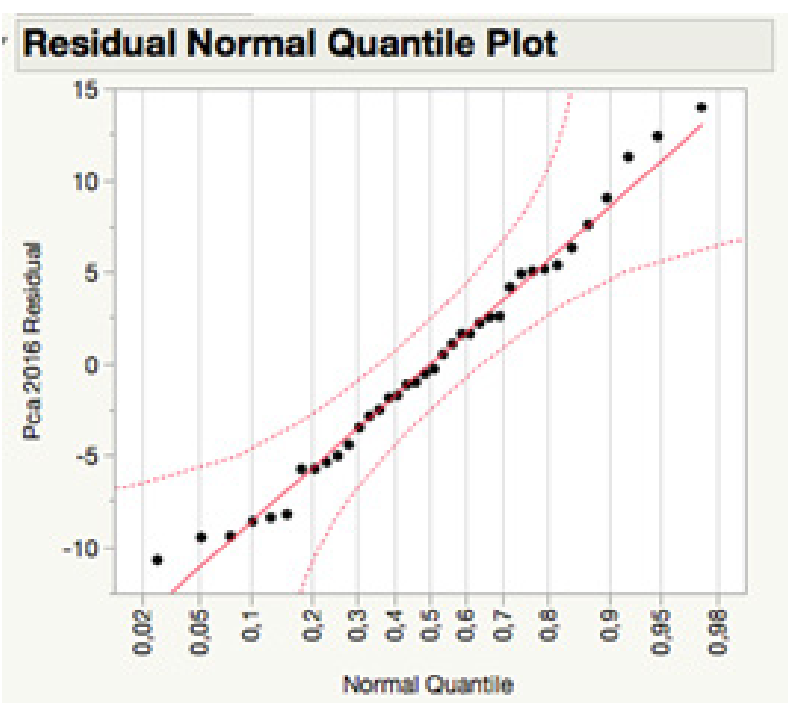

Figure 1. Q-Q plot in relation to PCa 2016 and quantile distribution of correlate variables.

The final test $\mathrm{F}$, calculated on the four variables, was found highly significant $(\mathrm{p}<0.001)$.

In this context, is possible to determine the Prediction Profiler which indicated the variable growing in proportion to the PCa as reported in Figure 2.

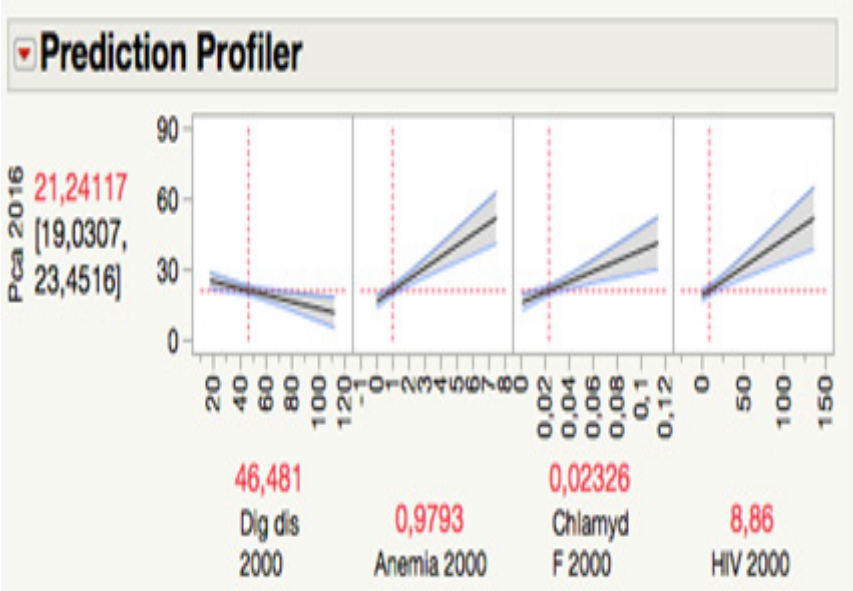

Figure 2. Prediction Profiler of the PCa correlated variables In red the mean values of ASDRs: anemia corresponds to IDA

The contribution given by IDA as a determinant for PCa was by far the most consistent (high slope and interval between 0 to 7.5 ASDRs), followed by HIV (high slope and interval between 0 to 150 ASDRs) and by chlamydia in females (more limited slope and the interval between 0 and 0.11 ASDRs). Digestive diseases resulted in very limited predictors (slightly negative slope and the interval between 20 and 110 ASDRs).

\section{The ASDRs of the diseases correlated with PCA}

Table7 reports only the data of variables with a statistically significant correlation $(\mathrm{P}<0.01)$ whereas all the diseases with non significant correlation were not reported. 


\begin{tabular}{|c|c|c|c|c|c|}
\hline & IDA & Chlamy females & HIV & Dig Dis & $\mathrm{PCa}$ \\
\hline GHE & 580 & 60 & 100 & 1210 & 740 \\
\hline Year & 2000 & 2000 & 2000 & 2000 & 2016 \\
\hline \multicolumn{6}{|l|}{ Country } \\
\hline Armenia & 0.312 & 0.0335 & 0.598 & 31.758 & 14.80 \\
\hline Australia & 0.215 & 0.0100 & 0.654 & 17.385 & 15.23 \\
\hline Austria & 0.034 & 0.0011 & 0.561 & 35.560 & 13.94 \\
\hline Bahamas & 0.011 & 0.0523 & 95.50 & 38.499 & 54.01 \\
\hline Belgium & 0.377 & 0.0077 & 0.496 & 30.285 & 13.36 \\
\hline Brazil & 2.337 & 0.0432 & 8.878 & 68.386 & 20.51 \\
\hline Brunei & 0.020 & 0.0329 & $\mathrm{nr}$ & 24.630 & 16.40 \\
\hline Canada & 0.504 & 0.0085 & 1.497 & 21.780 & 12.30 \\
\hline Chile & 0.408 & 0.0539 & 3.070 & 59.649 & 24.20 \\
\hline Croatia & 0.039 & 0.0021 & 0.147 & 55.090 & 20.02 \\
\hline Cuba & 0.504 & 0.0823 & 1.145 & 29.908 & 30.27 \\
\hline Czechia & 0.047 & 0.0037 & 0.023 & 38.752 & 16.48 \\
\hline Denmark & 0.936 & 0.0137 & 0.519 & 39.329 & 23.13 \\
\hline Estonia & 0.000 & 0.0247 & 0.186 & 48.149 & 28.44 \\
\hline Finland & 0.097 & 0.0085 & 0.166 & 31.913 & 15.59 \\
\hline France & 0.436 & 0.0093 & 1.816 & 32.760 & 13.21 \\
\hline Germany & 0.267 & 0.0043 & 0.650 & 38.934 & 15.38 \\
\hline Grenada & 7.432 & 0.0764 & 7.629 & 70.031 & 70.21 \\
\hline Guatemala & 3.555 & 0.0281 & 5.103 & 107.639 & 16.32 \\
\hline Hungary & $\mathrm{nr}$ & 0.0137 & 0.321 & 105.597 & 17.16 \\
\hline Iceland & 0.238 & $\mathrm{nr}$ & 17.724 & 10.518 & 21.06 \\
\hline Ireland & 0.608 & 0.0069 & 0.172 & 25.183 & 16.21 \\
\hline Israel & 2.121 & $\mathrm{nr}$ & 0.448 & 24.216 & 9.23 \\
\hline Italy & 0.560 & 0.0020 & 1.648 & 28.121 & 9.90 \\
\hline Japan & 0.175 & 0.0067 & 0.033 & 24.503 & 6.52 \\
\hline Kyrgyzstan & 0.726 & 0.0334 & 0.173 & 73.436 & 5.62 \\
\hline Latvia & 0.001 & 0.0489 & 0.145 & 43.680 & 26.88 \\
\hline Lithuania & 0.000 & 0.0380 & 0.193 & 38.446 & 25.85 \\
\hline Luxembourg & 0.551 & $\mathrm{nr}$ & 0.464 & 39.961 & 11.73 \\
\hline Malta & $\mathrm{nr}$ & $\mathrm{nr}$ & 0.247 & 18.980 & 10.79 \\
\hline Mauritius & 1.356 & 0.0289 & $\mathrm{nr}$ & 66.348 & 9.98 \\
\hline Mexico & 2.767 & 0.0198 & 4.875 & 91.912 & 13.97 \\
\hline Netherlands & 0.579 & 0.0083 & 0.777 & 24.197 & 17.94 \\
\hline New Zealand & 0.228 & $\mathrm{nr}$ & 0.532 & 13.622 & 16.44 \\
\hline Norway & 0.132 & 0.0064 & 0.337 & 20.08 & 22.76 \\
\hline Rep. of Korea & 0.461 & 0.0064 & 0.060 & 60.661 & 6.44 \\
\hline Moldova & 0.064 & 0.0631 & 1.096 & 112.498 & 13.38 \\
\hline Romania & 0.064 & 0.0090 & 2.028 & 66.716 & 13.13 \\
\hline St Vincent \&Grenedinas & 7.483 & 0.0142 & 35.405 & 42.181 & 84.63 \\
\hline Slovakia & 0.000 & 0.0086 & 0.038 & 64.086 & 22.72 \\
\hline Slovenia & 0.167 & $\mathrm{nr}$ & 0.189 & 60.143 & 21.00 \\
\hline Spain & 0.310 & 0.0045 & 3.988 & 35.138 & 11.42 \\
\hline Sweden & 0.301 & 0.0123 & 0.267 & 18.284 & 21.64 \\
\hline Switzerland & 0.374 & 0.0071 & 1.798 & 22.262 & 16.13 \\
\hline Macedonia & 0.164 & $\mathrm{nr}$ & 0.088 & 23.594 & 14.68 \\
\hline Trinidad \& Tobago & 3.697 & 0.0445 & 45.012 & 46.524 & 57.89 \\
\hline
\end{tabular}




\begin{tabular}{|l|l|l|l|l|l|}
\hline United Kingdom & 0.168 & 0.0138 & 0.345 & 27.846 & 17.53 \\
\hline United States of America & 0.427 & 0.0091 & 4.686 & 29.913 & 12.84 \\
\hline Uzbekistan & 0.345 & 0.0062 & 0.187 & 59.338 & 1.96 \\
\hline Mean & 0.8711 & 0.0240 & 7.2669 & 43.5692 & 20.2614 \\
\hline SD & 1.62870 & 0.02531 & 22.43586 & 26.73397 & 15.54707 \\
\hline
\end{tabular}

Table 7. ASDRs in 2000 with statistically significant correlation $(\mathrm{p}<0.01)$ with ASDRs for PCa in 2016

GHE = Global Health Evaluation; Chlamy = chlamydia in females; HIV = HIV/AIDS; Dig Dis = digestive diseases; PCa = prostate cancer; $\mathrm{nr}=$ not reported

\section{Discussion}

The present analysis may have some limitations due to the number of males because in 2016 the totality of the WHO listed countries (185) consisted of 3733.368 million, whereas the number of males within the 49 SC was 721.977 million, and the PCa as CRD was $44.1 \%$. However, despite these differences, the figures of the present study can be considered a good sample to test the correlations between PCa and other diseases. Another limitation could be the life expectancy (LE). In 185 countries was $70.8 \pm 9.01$ years, whereas in the 49 SC countries it was $78.4 \pm$ 35.24 [23]. Age is known as a prominent factor for PCa and ASDRs values minimize this bias. The average gross profit (GP) can be also a bias. For the 49 SC in 2016 it was 32,753 $\pm 19,510$ USD compared to $15,374 \pm 24,855$ USD of the remaining countries [23] and this difference can be determinant for life expectancy in terms of prolonging the survival rate in case of cancer. Another limitation can be the period of 16 years used for the calculations. Despite the time needed for PCa development up to death is not known, the period of 16 years was considered sufficient by other authors [8]. The choice of ASDRs as the main variable can be a further limitation because the values sometimes represent a cluster of diseases. In particular, IDA could be more consistent as a symptom within other illnesses determining death. This is also true for some of the other variables (e.g. chlamydia or gonorrhea) which can be concomitant with other severe diseases (e.g. cardiovascular, metabolic). However, as declared by WHO, the cause of death allows us to compare the mortalities among countries, and ASDRs is a reliable measure for the "diseases dimension". Comparing the years 2000 and 2016, with the exception of $\mathrm{HIV}, \mathrm{PCa}$ and all the other diseases were reduced indicating that the increase of the survival was possibly due to a general health care improvement. A part of these limitations, the results of the present analysis address some interesting points. Four diseases were apparently correlated to PCA were: chlamydia in females, digestive diseases, HIV, and IDA. Each disease needs a specific comment. Chlamydia was considered by WHO the most important STD affecting > 130 million, recognized to have a direct impact on infertility, pregnancy, cancer, and also to facilitate the sexual transmission of HIV [24].
WHO planned a program consisting of 4 phases, wherein phase 2 indicates that among the usual measures (e.g. condoms, antibiotics) the intervention with vaccines should be appropriate.

The WHO records do not list chlamydia as a male disease, despite the fact males are also responsible for bacterial spreading. In the present analysis, chlamydia in females was shown to be the only infection correlated with PCa, and the hypothesis was that once males are contaminated the infection remains latent but at the same time it can possibly, slowly modify the prostate environment up to the formation of cancer cells.

The WHO records do not differentiate the type of chlamydia (e.g. C. trachomatis or pneumoniae) and IDA can be a protective mechanism against infection since iron is needed for bacterial growth and survival [25]. Our findings confirm a possible statistical connection between IDA and chlamydia and indicate IDA as a possible concomitant cause and not as a consequence. Other infectious diseases such as TBC, syphilis, gonorrhea, were never correlated and most of the other infections (e.g. trichomoniasis) were rarely represented in the 49 SC countries.

The digestive diseases listed by WHO consists of many illnesses being a gastric ulcer and cirrhosis the most represented in the 49 SC, whereas all the other diseases (appendicitis, gastroduodenal diseases, paralytic ileus and intestinal obstructions, inflammatory bowel diseases, gallbladder, and biliary diseases, pancreatitis) are much less represented. Gastric-duodenal ulcer and cirrhosis were analyzed separately and no correlation with PCa was shown indicating that these diseases can be ruled out.

The relationship of $\mathrm{PCa}$ with other digestive diseases remains obscure, and no reliable hypothesis can be drawn because in the Prediction profile analysis their importance was minimal.

$\mathrm{HIV}$ is a disease associated with immune depression [26], characterized by a chronic inflammation that persists even during antiretroviral therapy (ART). This condition can be the ground for the development of PCa. IDA was shown to be prevalent in HIV patients [27] and even following active ART is associated with a higher risk of mortality [28]. 


\section{The issue of IDA}

IDA affects about 1.24 billion people [29]-most are children and women from underdeveloped countries-and have an impact on many diseases including cancers.

However, anemia of different types could be determined by therapies for PCa. In this instance, it could "concentrate" the cases acting as a filter. Because of this, IDA could be considered a "consequence" and not a "cause". In the case of PCa, one of the most common therapies is the androgen deprivation therapy (ADT) which is recognized to cause a temporally normochromic normocytic anemia and not IDA [30, 31]. In about $90 \%$ of the cases, anemia due to ADT can be corrected with the use of recombinant erythropoietin; the condition is reversible after discontinuation of hormonal therapy [32-34]. Furthermore, altered lipid profile and insulin resistance are also common adverse effects [35]. Anemia, in general, has been described by approximately $30 \%$ of PCa patients with metastases to the bone marrow at the time of the diagnosis [36]. A part of ADT, several other factors causing anemia have to be considered consisting of hematuria, radiotherapy, inflammatory cytokines, chronic diseases, poor nutritional status, and orchiectomy. All these conditions may cause mainly a leucoerythroblastic anemia.

However, IDA is classically defined as hypochromic microcytic anemia, and because of this, the impact of ATD can be disregarded. Furthermore, in our patients of the San Valentino epidemiological study, IDA could not have been caused by drugs (they were free of any therapy). Despite this, in the case of PCa one may not rule out completely the influence of other therapies (e.g. radiation, chemotherapy) causing IDA.

A large part of the world male population is affected by IDA (about 7-8 \% of the males), and many chronic diseases are characterized by this symptom [37], particularly in those countries where foods are not sufficient either in terms of quantity and quality to ensure an appropriate iron intake.

Lack of food was not the case of most 49 SC, whereas the dietary intake (e.g. meat, vegetables, cereals, beverages) could be one of the causes of iron deficiency.

Iron is important for blood-red cell production that will be reduced in case of an impaired inflow of iron from storage sites into the transporting pool red cells [29]. The lack of iron does not affected cells alone since in general is consistent with the reduction of cellular proliferation, DNA synthesis, and the activity of iron-containing/dependent enzymes involved in the microbial killing.

As a rule, bacterial infections are followed by serum iron reduction which predisposes to infection morbidity and mortality [38]. In experimentally induced IDA, morbidity and mortality due to bacterial challenge increase several times [39] due to the impairment of cell-mediated immunity, and the intracellular bacterial killing capacity of polymorphonuclear cells (PMNs).

It is believed that viruses, unlike bacteria do not require iron as a growth factor [40]. Conversely, the availability of the free iron is a critical determinant for bacterial multiplication, such that pathogen and host compete for iron $[41,42]$ and the host defense mechanism is aimed to deprive microbes of iron.

The problem that can arise is the influence of iron on viral growth. The PMNs, also in case of immune depression, continue to collect old erythrocytes and use their iron to replicate. However, in the case of viral infection, they may also contain a virus, which takes an indirect advantage from PMNs replication to spread the infection. The consequence is that viruses will take an indirect advantage from IDA which was shown to be an independent predictive marker for an unfavorable HIV prognosis [43]. On the other hand, iron was also considered to favor neoplastic growth [44] and in this case, IDA could have a favorable aspect to counteract PCa.

This "Janus", two faces behavior of iron indicates that IDA could be considered as a protective mechanism against cancer but at the same time it may favor the pathogen micro-organism invasion which can trigger PCa development. However, considering the complexity of the present analysis, IDA seems to be more prominent as cause than as effect.

\section{Conclusions}

From the analysis of the data based on the WHO record concerning the 49 SC, three diseases were found correlated with PCa: IDA, HIV, and chlamydia in females. A sort of "road map" for PCa can be hypothesized.

The starting point can be IDA which allows the infective invasion caused by chlamydia or viruses such as HIV. This is the first time that chlamydia is considered one of the conditions responsible for $\mathrm{PCa}$. The competence of the immune system may be compromised by IDA and the consequence is a reduction of the defense against the PCa. The increase of immunological capacity opens an avenue for specific vaccination against chlamydia (particularly for males). In the end, the presence of IDA in males stimulates a deeper and specific analysis of the patients.

\section{Acknowledgments}

We are thankful to the WHO that allowed the public availability of the database: the use of these data can be extremely helpful for authors who need details on the epidemiology of different diseases. 


\section{Author contributions}

Cornelli $U$ conceived the trial, retrieved some of the WHO data and wrote the article; Belcaro G retrieved part of the WHO data; Martino Recchia was responsible for the statistical analysis. All the authors read and approved the final manuscript.

\section{References}

1) Cesarone MR, Belcaro G, Nicolaides AN, et al. (1997) Epidemiology and costs of venous diseases in central Italy. The San Valentino Venous Disease project. Angiology 48: 593-593.

2) CesaroneBelcaro G, Nicolaides AN et al. (2000) San Valentino epidemiologic vascular project. Angiology 51: S65-S68.

3) Taitt HE (2018) Global trends and prostate cancer: a review of incidence, detection, and mortality as influenced by race, ethnicity, and geographic location. Am J Men's Health 6: 1807-1823.

4) Nelson WG, De Marzo AM, Isaacs WB (2003) Prostate cancer NEJM 366-381.

5) Velcheti V, Karink S, Bardot SF, Pralash ON (2008) Pathogenesis of prostate cancer: lessons from basic research. Ochsner J 4: 213-218.

6) Mustafa M, Salih AF, Illzam EM, et al. (2016) Prostate cancer: pathophysiology, diagnosis, and prognosis. IOSR Journal of Dental and Med Sciences 15: 4-11.

7) Rebbeck TR (2017) Prostate cancer genetics: variation by race, ethnicity, and geography. Semin Radiat Oncol 27: 3-10.

8) Hugosson J, Robol MJ, Mànsson M, et al. (2019) A 16-years follow-up of the European Randomized study of screening for prostate cancer. Eur Urol 76: 43-51.

9) Gomella LG (2017) Prostate cancer statistics: anything you want them to be. Can J Urol 24: 8603-8604.

10) Klein J, von demKnesebeck O (2015) Socioeconomic inequalities in prostate cancer survival: a review of the evidence and explanatory factors. Soc Sci Med 142: 9-18.

11) Dasgupta P, Baade PD, Altken JF, et al. (2019) Geographical variations in prostate cancer outcomes: a systematic review of international evidence. Front Oncol 9: art 238.
12) Roy S, Morgan SC (2019) Who dies from prostate cancer? An analysis of the surveillance epidemiology and end results database. Clin Oncol (R Coll Radiol) 31: 630-636.

13) Robinson D, Garmo H, Lissbrant IF, et al. (2018) Prostate cancer death after radiotherapy or radical prostatectomy: a nationwide population-based observational study. Eur Urol 73: 502-511.

14) Dennis LK, Lynch CF, Torner JC (2002) Epidemiologic association between prostatitis and prostate cancer. Urology 60: 78-83.

15) Sutcliffe S, Giovannucci E, De Marzo AM, et. al. (2006) Gonorrhea, syphilis, clinical prostatitis, and the risk of prostate cancer. Cancer Epidemiol Biomarkers Prev 15: 2160-2166.

16) Caini S, Gandini S, Dudas M et al. (2014) Sexually transmitted infections and prostate cancer risk: a systematic review and meta-analysis. Cancer Epidemiol 38: 329-338.

17) (2018) Global Health Estimates (2016) death by Cause, Age, Sex, by Country and by Region 2000-2016. Geneva World Health Organization.

18) Albert A and Harris E (1987) Multivariate interpretation of clinical laboratory data. Marcel Dekker, New York 1987.

19) Allen D and Cady F (1982) Analyzing experimental data by regression. Wadwsworth.

20) Besley, Kuh and WelshM (1980) Regression diagnostics. John Wiley \& Sons.

21) Cook D, and Weisberg S (1982) Residual and influence in regression. Chapman and Hall.

22) Draper NR and Smith H (1966) Applied regression analysis. John Wiley \& Sons.

23) Cornelli U, Recchia M, Grossi E, Belcaro G (2018) Life expectancy does not depend on classical ecological variables: stochastic and nonstochastic analysis. GSL Public Health Epidemiol 1: 104-109.

24) (2016) WHO guidelines for the treatment of Chlamydia trachomatis 
25) Al-Younes HM, Rdel T, Brinkmann V et al. (2001) Low iron availability modulates the course of Chlamydia pneumoniae infection. Cell Microbiol 3: 427-437.

26) Barouch DH, Deeks SG (2014) Immunologic strategies for HIV-1 remission and eradication. Science 345: 169-174.

27) Frosh AEP, Ayodo G, Odhiambo EO et al. (2018) Iron deficiency is prevalent among HIV-infected Kenian adults and is better measured by soluble transferrin receptor than ferritin. Am J Trop Med 99: 439-444.

28) Haider BA, Spiegelman D, Hetzmark E et al. (2019) Anemia, iron deficiency, and iron supplementation in relation to mortality among HIV-infected patients receiving highly active antiretroviral therapy in Tanzania. Am J Trp Med Hyg 100: 1512-1520.

29) Stelle I, Kalea AZ, Pereira DIA (2019) Iron deficiency anemia: experiences and challenges. Proc Nutr Soc 78: 19-26.

30) Strum SB, McDermed JE, Scholz MC et al. (1997) Anaemia associated with androgen deprivation in patients with prostate cancer receiving combined hormone blockade. Br J Urol 79: $933-$ 941.

31) Curtis KK, Adam TJ, Chen SC et al. (2008) Anaemia following initiation of androgen deprivation therapy for metastatic cancer: a retrospective chart review. Aging Male 11: 157-161.

32) Ahmadi H, Daneshmand S (2003) Androgen deprivation therapy: evidence-based management of side effects. BJU international 111: 543-458.

33) Higano CS (2003) Side effects on androgen deprivation therapy: monitoring and minimizing toxicity. Urology 61: 32-38.

34) Hicks BM, Lill-Dori AJ, Yin H, et al. (2017) Androgen deprivation therapy and risk of anemia in men with prostate cancer. Epidemiology 28: 712-718.

35) Owen PJ, Daly RM, Liningston PM, Fraser SF (2017) Lifestyle guidelines for managing adverse effects on bone health and body composition in men treated with androgen deprivation therapy for prostate cancer: an update. Prostate Cancer and Prostatic Diseases 20: 137-145.

36) Nalesnik JG, Mysliwiech AG, Camby-Hagino E (2004) Ane- mia in men with advanced prostate cancer: incidence, etiology, and treatment. Rev Urol 6: 1-4.

37) Lopez A, Cacoub P, Macdougall IC, Peyrin-Biroulet L (2016) Lancet 387: 907-916.

38) Keusch GT (1990) Micronutrients and susceptibility to infection. Ann N Y Acad Sci 587: 181-188.

39) Chandra RK, Au B, Woodford G, Hyam P (1976) Ciba Found Symp 51: 249-268.

40) Weinberg ED (1974) Iron and susceptibility to infectious disease Science 184: 952-956.

41) Ganzoni AM, Puschmann (1978) Iron deficiency in infection. Haematol Blood Transfus 21: 95-104.

42) Ganz T (2018) Iron in infection. Int J Hematol 107: 7-15.

43) Moore RD, Keruly JC, Chairsson RE (1999) Anemia and survival in HIV infections. J Acquir Immune Defic Syndr 19: 29-33.

44) Weinberg ED (1996) The role of iron in cancer. Eur J Cancer Prev 5: 19-36.

Submit your manuscript to a JScholar journal and benefit from:

ๆ Convenient online submission

ฯ Rigorous peer review

9 Immediate publication on acceptance

- Open access: articles freely available online

ฯ High visibility within the field

- Better discount for your subsequent articles

Submit your manuscript at http://www.jscholaronline.org/submit-manuscript.php 